\title{
Algorithm of Strength Calculation of Drive Elements of a Roller Conveyor
}

\author{
Mariya Androsenko*, Nail Tyuteryakov, Ekaterina Kulikova, Lyubov Deryabina and Ivan
} Krayniy

Nosov Magnitogorsk State Technical University, Lenin Avenue 38, Magnitogorsk, postcode 455000, Russia

\begin{abstract}
The paper shows an algorithm for determining the load on the electric motor of run-out conveyor starting from determination of the first moment of no load operation during slab conveying, slipping torque of the rollers along the surface of the conveyed billet and ending with the choice of the electric motor. It also covers an algorithm for strength calculations of the run-out conveyor roller, which includes the calculation of the moments and forces acting on the conveyor roller and its supports, the calculation of static strength and torsion strength, calculation of roller deflection of the conveyor rollers as well as the selection and verification calculation of conveyor roller bearings.
\end{abstract}

\section{Introduction}

Roller conveyor (roller table) is a mechanism for conveying loads horizontally or at a slight angle. It consists of a frame and a group of rollers, axes of which are fixed in it with roller bearings.

Roller conveyors are subdivided into non-driven ones with manual movement of loads or under the influence of earth's gravity and consisting of rollers fixed to a frame with different distances between the centres of the roller axes depending on the length and weight of the load being moved and roller conveyors driven by means of a motor and mechanical transmissions.

\section{Main part}

Figure 1 shows the drawing of one of the conveyor roller drives of 5 strand billet caster. It is a variant of a roller table individually driven by a geared motor.

\footnotetext{
* Corresponding author: Manechka.05@mail.ru
} 


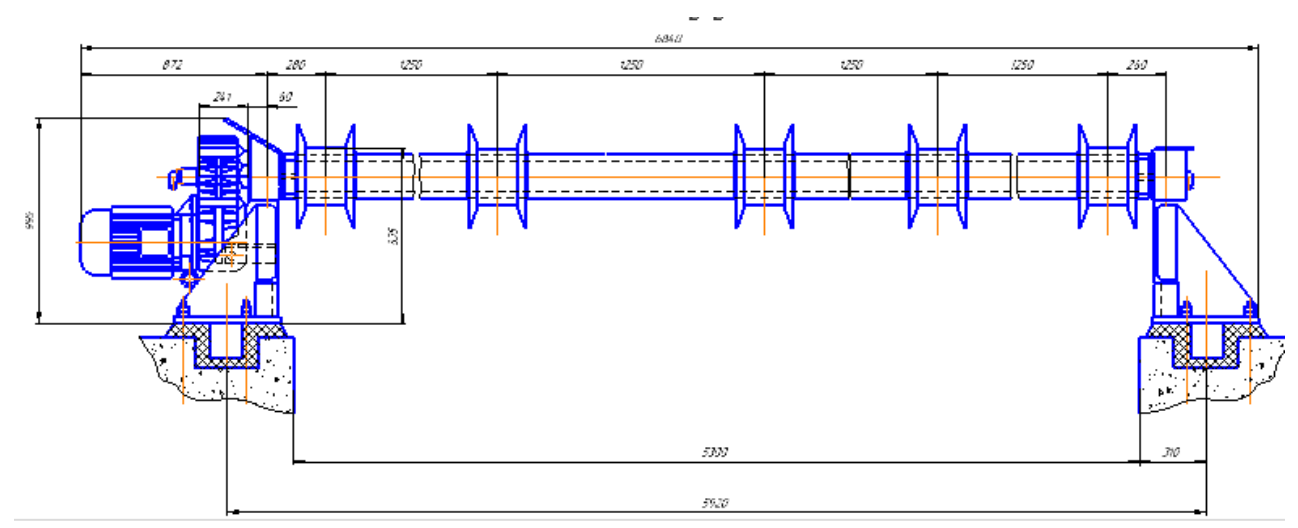

Fig. 1. Drawing of the roller drive of a billet caster run-out roller table.

The algorithm for estimation of load on electrical motor of run-out conveyor is the calculation of:

- The first moment of no load operation of a roller conveyor applied to a motor shaft $\mathrm{M}_{\mathrm{XP}}, \mathrm{N}$ m;

- The first moment when conveying the slab applied to a motor shaft $\mathrm{M}_{\mathrm{mp}}, \mathrm{N} \mathrm{m}$;

- Slipping torque of the rollers along the surface of the conveyed billet applied to an electric motor shaft $\mathrm{M} \sigma, \mathrm{Nm}$;

- Moment of additional static resistance (the moment of friction of the metal against the side framing of the roller table, the moment of additional static resistance when transporting the billet with the end bent down) $\mathrm{M}_{д}, \mathrm{Nm}$;

- Total angular momentum of static resistance at slipping $\mathrm{M}$ c. $\sigma, \mathrm{Nm}$.

First moment of roller no load operation is calculated as following [1]:

$$
M_{x . p}=\frac{G_{p} \cdot d_{u} \cdot \mu_{u}}{2 \cdot i \cdot \eta_{x}} .
$$

where:

$\mathrm{G}_{\mathrm{p}}$ - weight of one roller, $\mathrm{H}$;

$\mathrm{d}_{\mathrm{w}}-$ roller neck diameter, $\mathrm{m}$;

$\mu_{\mathrm{w}}$ - friction coefficient in an antifriction bearing;

$\eta_{\mathrm{x}}$ - Efficiency factor of a gear box at no load operation;

$\mathrm{i}$ - gear box ratio.

The first moment when conveying the slab applied to a motor shaft $\mathrm{M}_{\mathrm{mp}}$ is calculated as following:

$$
M_{m p}=\frac{G_{s}\left(\frac{d_{u}}{2} \mu_{u}+f \cdot 10^{-2}\right)}{i \cdot \eta_{m p}} .
$$

where

$f$ - coefficient of rolling friction of metal on rollers, $\mathrm{cm}$;

$\eta_{\mathrm{Tp}}$ - efficiency factor of a gear box at conveying the metal along the roller table;

$\mathrm{G}_{\mathrm{m}}$ - the weight of the metal per conveyor roller [2], $\mathrm{H}$;

$$
G_{M}=n \cdot L \cdot a \cdot \sigma \cdot \rho \text {. }
$$

where:

$\mathrm{n}$ - the number of billets at the roller table at the same time, pcs.;

$\mathrm{L}$ - the length of the billet per roller, $\mathrm{m}$;

a- Side width of the billet, $\mathrm{m}$; 
б - Side height of the billet, $\mathrm{m}$;

$\rho$ - billet material density, $\mathrm{kg} / \mathrm{m}^{3}$.

Slipping torque of the rollers along the surface of the conveyed billet applied to an electric motor shaft is calculated as following:

$$
M_{\sigma}=\frac{G_{M} \cdot \frac{d_{p}}{2} \cdot \mu_{\sigma}}{i \cdot \eta_{u}} .
$$

where:

$\mathrm{d}_{\mathrm{p}}$ - conveyor roller diameter, $\mathrm{m}$;

$\mu_{\sigma}$ - friction coefficient at slipping;

$\eta_{\mathrm{x}}$ - Efficiency factor of a gear box at nominal load.

Total angular momentum of static resistance at slipping is calculated as following:

$$
M_{c . \sigma}=M_{x . p}+M_{\sigma} .
$$

Excess torque emerges when conveying the billet with the bent

$$
M_{\text {д }}=\frac{P_{T . O} \cdot d_{p}}{2 \cdot i \cdot \eta_{m p}} .
$$

where:

$\mathrm{P}_{\text {T.O }}$ is the circumferential force required to convey the billet with the end bent down.

The additional load on the roller arising in this case is shown in the force diagram of Figure 2.

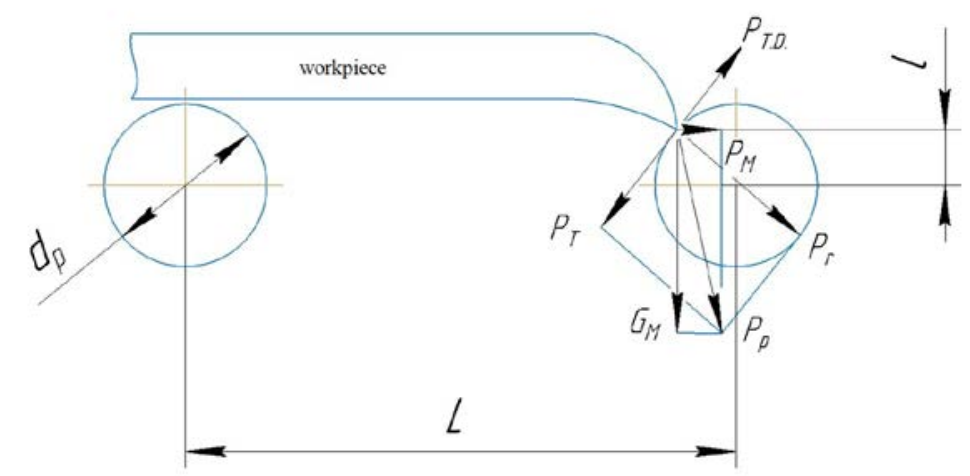

$\mathrm{G}_{\mathrm{m}}$ - vertical component of the force applied to the roller from the weight of the billet, $\mathrm{N} ; \mathrm{P}_{\mathrm{M}}$ total force transmitted to the billets by the upstream rollers in the direction of its movement, $\mathrm{N} ; \mathrm{P}_{\mathrm{p}}$ -

resultant of forces with which the metal acts on the roller, $\mathrm{N} ; \mathrm{P}_{\mathrm{N}}, \mathrm{P}_{\mathrm{T}}$ - normal and tangential components of the resultant force, $\mathrm{N} ; \mathrm{l}$ - distance between the horizontal axis of the roller and the bent end of the billet, $m ; d_{p}$ - conveyor roller diameter, $m$

Fig. 2. The scheme of influence of the forces when transporting the billet with the end bent down.

The smallest value of the force $\mathrm{P}_{\text {т. }}$ without taking into account the influence of the kinetic energy stored in the transported metal, at the maximum bending of the strip is calculated as following:

Analyzing the forces acting on the direction of the force $\mathrm{R}_{\mathrm{T} . \mathrm{O}}$, we get:

$$
P_{T . O}+P_{M} \cdot \sin \alpha-G_{M} \cdot \cos \alpha=0 .
$$


Thus if we take into account that $\sin \alpha=\frac{2 l}{d_{p}}$, we get:

$$
P_{T . O}=G_{M} \sqrt{1-\left(\frac{2 l}{d_{p}}\right)^{2}}-P_{M} \frac{2 l}{d_{p}}
$$

Force $\mathrm{P}_{\mathrm{M}}$ transferred to the strip in the direction of its upstream roller movement arises from the slipping and can be calculated as following:

$$
P_{M}=G_{M} \cdot \mu_{\sigma}
$$

Taking into account all the above values and equalities, after the conversion, we obtain the following equations to calculate the additional moment when transporting a strip with a bent end:

$$
M_{\text {д }}=\frac{G_{M}}{i \eta_{m p}} \cdot\left(\frac{1}{2} \sqrt{d_{p}^{2}-4 l^{2}}-l \mu_{\sigma}\right) .
$$

Total static moment during metal transportation along the roller table, taking into account additional resistances:

$$
M_{c . m}=M_{x . p}+M_{m p}+M_{\text {д }} \cdot
$$

Maximum motor power corresponding to the maximum value of the total static moment of:

$$
P_{\max }=\frac{M_{c . m} \cdot n \cdot i}{9750}
$$

where:

$\mathrm{n}$ - roller table rotary velocity, $\min ^{-1}$,

$\mathrm{i}$ - motor reduction unit ratio.

AC motors with coaxial cylindrical double-reduction gear unit are used for the roller tables of this type.

Motor reduction units of this type are designed and produced in one-piece heavy duty housing. The housing and flange are made of high-strength cast iron G20 UNI 5007, excluding gearboxes and motor reduction unit of sizes 25, 32, 35, 40 and 50/1 as well as for elements for which aluminium SG-AISi UNI 1706 is used. The input and output shafts are manufactured from steel 16CrNi4 UNI 7846 which undergoes post-heat treatment.

The algorithm for strength calculations of the run-out conveyor [3]:

- Calculation of the moments and forces acting on the conveyor roller and its supports;

- Calculation of static strength for the conveyor roller;

- Calculation of torsion strength for the conveyor roller;

- Calculation of the deflection of a conveyor roller;

- Selection and verification calculation of conveyor roller bearing.

Loading diagram of the conveyor roller is shown in figure 3. 


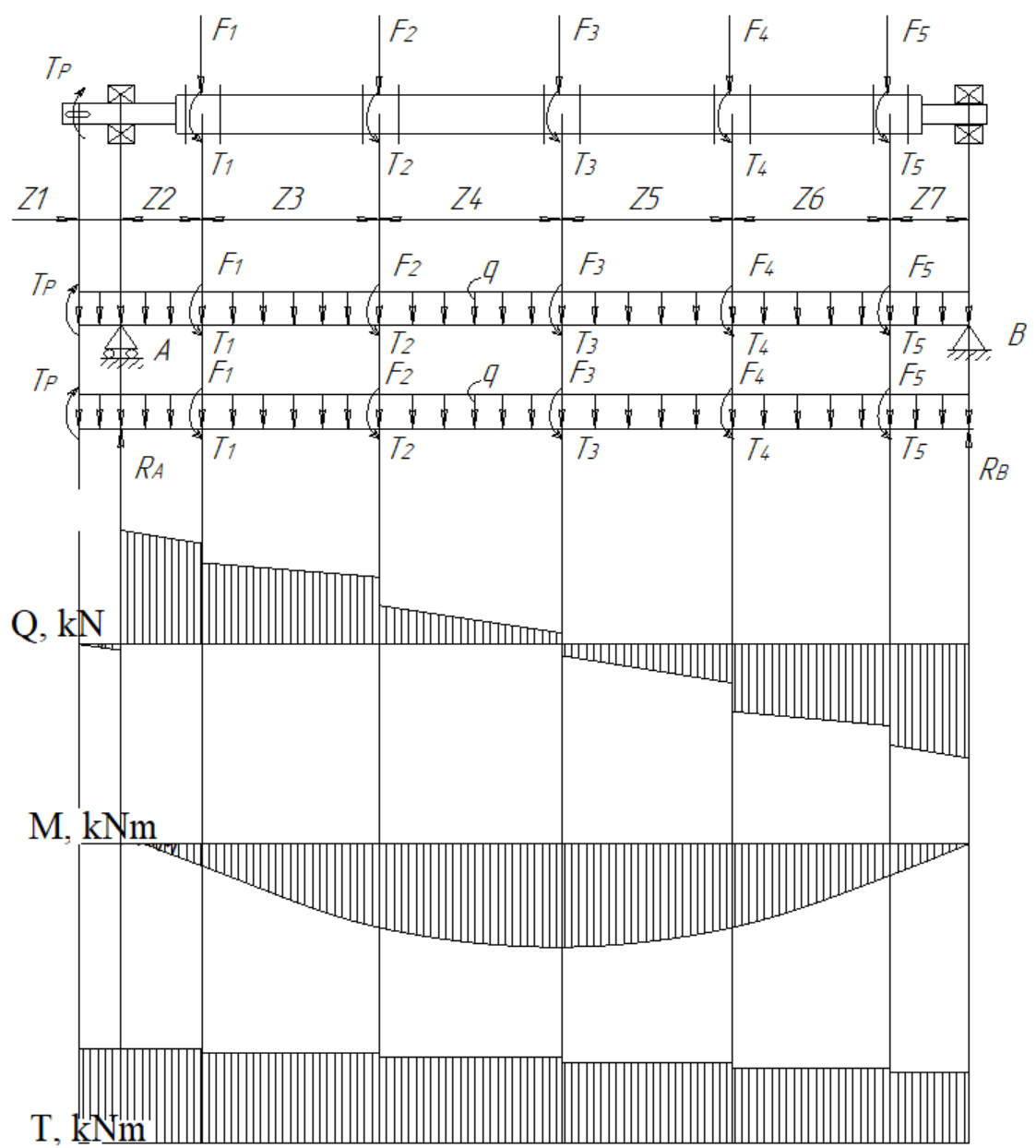

Fig. 3. Loading diagram of the conveyor roller.

Force which is caused by the weight of the billet and which acts on the roller:

$$
F=F_{1}=F_{2}=F_{3}=F_{4}=F_{5}=\frac{G_{M}}{5} .
$$

The resisting moment from one billet during slipping is calculated as following:

$$
T=T_{1}=T_{2}=T_{3}=T_{4}=T_{5}=\frac{F \cdot \mu_{6} \cdot d_{p}}{2} .
$$

where:

$\mathrm{q}$ - distributed force caused by roller weight, $\mathrm{N}$.

Support reaction force at points A and B can be calculated as following:

$$
\begin{aligned}
& \sum M_{B}=0-\text { for } \mathrm{R}_{\mathrm{A}} ; \\
& \sum M_{A}=0-\text { for } \mathrm{R}_{\mathrm{B}} .
\end{aligned}
$$

Calculation verification is performed: 


$$
\sum F_{i}(y)=0
$$

Method of sections [4] with the length of parts $\mathrm{Z} 1 \div \mathrm{Z7}$ is used to make diagrams of resisting moments, torque moments and transverse forces.

Part $1, \mathrm{z} \rightarrow 0 \div \mathrm{Z} 1:$

$$
\begin{gathered}
Q=-q \cdot z, \\
M=-q \cdot z^{2} / 2, \\
T=T p
\end{gathered}
$$

Part $2, \mathrm{z} \rightarrow 0 \div \mathrm{Z} 2$ :

$$
\begin{gathered}
Q=-q \cdot(0,16+z)+R_{A}, \\
M=\frac{-q \cdot(0,16+z)^{2}}{2}+R_{A} \cdot z \\
T=T p
\end{gathered}
$$

3 Part, $\mathrm{z} \rightarrow 0 \div \mathrm{Z} 3$ :

$$
\begin{gathered}
Q=-q \cdot(0,44+z)+R_{A}-F_{1} \\
M=\frac{-q \cdot(0,44+z)^{2}}{2}+R_{A} \cdot(0,28+z)-F_{1} \cdot z \\
T=T p-T_{1} .
\end{gathered}
$$

$4 \quad$ Part, $\mathrm{z} \rightarrow 0 \div \mathrm{Z} 4:$

$$
\begin{gathered}
Q=-q \cdot(1,69+z)+R_{A}-F_{1}-F_{2} \\
M=\frac{-q \cdot(1,69+z)^{2}}{2}+R_{A} \cdot(1,53+z)-F_{1} \cdot(1,25+z)-F_{2} \cdot z \\
T=T p-T_{1 .}-T_{2}
\end{gathered}
$$

Part $5, \mathrm{z} \rightarrow 0 \div \mathrm{Z5}:$

$$
\begin{gathered}
Q=-q \cdot(2,94+z)+R_{A}-F_{1}-F_{2}-F_{3} \\
M=\frac{-q \cdot(2,94+z)^{2}}{2}+R_{A} \cdot(2,78+z)-F_{1} \cdot(2,5+z)-F_{2} \cdot(1,25+z)-F_{3} \cdot z . \\
T=T p-T_{1}-T_{2}-T_{3}
\end{gathered}
$$

$6 \quad$ Part, $\mathrm{z} \rightarrow 0 \div \mathrm{Z} 6$ :

$$
\begin{gathered}
Q=-q \cdot(4,19+z)+R_{A}-F_{1}-F_{2}-F_{3}-F_{4} . \\
M=\frac{-q \cdot(4,19+z)^{2}}{2}+R_{A} \cdot(4,03+z)-F_{1} \cdot(3,75+z)-F_{2} \cdot(2,5+z)-F_{3} \cdot(1,25+z)-F_{4} \cdot z . \\
T=T p-T_{1} \cdot-T_{2}-T_{3}-T_{4}
\end{gathered}
$$

$7 \quad$ Part, $\mathrm{z} \rightarrow 0 \div \mathrm{Z7}$ :

$$
Q=-q \cdot(5,44+z)+R_{A}-F_{1}-F_{2}-F_{3}-F_{4}-F_{5},
$$




$$
\begin{gathered}
M=\frac{-q \cdot(5,44+z)^{2}}{2}+R_{A} \cdot(5,28+z)-F_{1} \cdot(5+z)- \\
-F_{2} \cdot(3,75+z)-F_{3} \cdot(2,5+z)-F_{4} \cdot(1,25+z)-F_{5} \cdot z \\
T=T p-T_{1 .}-T_{2}-T_{3}-T_{4}-T_{5}
\end{gathered}
$$

Based on the data obtained during the calculations, the diagrams of transverse forces Q, resisting moments $\mathrm{M}$ and torque moments $\mathrm{T}$ are made.

According to the diagram (M) in Figure 3, the static strength calculation is carried out in the section where the bending moment has a maximum value.

Normal stresses in the critical section of the roller are calculated as following:

$$
\sigma_{\text {изг }}=\frac{\kappa_{\text {nep }} \cdot M}{W} .
$$

where $\mathrm{W}$ - resisting moment of the roller table roller section, $\mathrm{m}^{3}$;

$\mathrm{k}_{\text {пер }}$ - overload factor $\left(\mathrm{k}_{\text {пер }}=1,47\right)$.

$$
W=\frac{\pi \cdot D^{3}}{32}\left(1-\frac{d^{4}}{D^{4}}\right)
$$

where:

$\mathrm{D}$ - roller table roller outer diameter, $\mathrm{m}$;

$\mathrm{d}$ - diameter of the hole in the roller, for supplying water for cooling, $\mathrm{m}$.

Shear stresses in the critical section of the roller are calculated as following

$$
\tau_{\text {изг }}=\frac{\kappa_{\text {nep }} \cdot 4 \cdot Q}{3 \cdot S} .
$$

where S - critical section area, $\mathrm{m}^{2}$.

$$
S=\frac{\pi \cdot D^{2}}{4}-\frac{\pi \cdot d^{2}}{4} .
$$

General safety factor for the yield strength $S_{T}$ under the combined action of normal and shear stresses:

$$
\begin{gathered}
S_{T}=\frac{S_{T \sigma} \cdot S_{T \tau}}{\sqrt{S_{T \sigma}^{2}+S_{T \tau}^{2}}} ; \\
S_{T \sigma}=\frac{\sigma_{T}}{\sigma_{\text {изг }}} .
\end{gathered}
$$

where:

$\mathrm{S}_{\mathrm{T} \sigma}$ are the safety factors for normal stresses;

$\sigma_{\mathrm{T}}$ - bending yield point of roller material, MPa;

$\sigma_{\text {изг }}-$ normal bending stresses, MPa;

$\mathrm{S}_{\mathrm{T} \tau}$ - safety factor for shear stresses:

$$
S_{T \tau}=\frac{\tau_{T}}{\tau_{\text {изг }}}
$$


where:

$\tau_{\mathrm{T}}$ - torsion yield of roller material, MPa;

$\tau_{\text {изг }}$ - shear stresses due to bending, MPa.

Static strength is considered to be ensured if $\mathrm{S}_{\mathrm{T}} \geq\left[\mathrm{S}_{\mathrm{T}}\right]$. $\left[\mathrm{S}_{\mathrm{T}}\right]$.

Safety factor under the combined action of normal and shear stresses $n_{T}=S_{T}$ /

The strength of the roller table roller shaft operating in torsion is considered to be ensured if the maximum shear stresses $\tau_{\max }$ arising in its critical cross section do not exceed the permissible $\left[\tau_{\mathrm{K}}\right]_{[}[7]$ :

$$
\tau_{\max } \leq\left[\tau_{k}\right]
$$

Insignificant (up to $5 \ldots 6 \%$ ) exceedance of the calculated voltage over the permissible one is not dangerous.

The maximum stresses arise at the points of the cross-sectional outline. They can be calculated as following:

$$
\tau_{\text {max }}=\frac{T}{W_{p}} .
$$

where:

$\mathrm{W}_{\mathrm{p}}-$ polar section modulus, $\mathrm{m}^{3}$,

$$
W_{p}=\frac{\pi \cdot D^{3}}{16}\left(1-\frac{d^{4}}{D^{4}}\right)
$$

The torsional yield point is related to the tensile yield point as following:

$$
\left.\left[\tau_{\kappa}\right] \approx(0,55 \ldots 0,60) \mid \sigma_{p}\right\rfloor
$$

To calculate the deflection $\mathrm{f}$ of fully supported rollers, the following formula can be used:

where:

$$
f=M / E \cdot I \leq[f]
$$

$M$ - is a bending moment in the critical section, Nm;

$E$ - elasticity modulus (Young's modulus), which is a tabular value, MPa;

$I$ - second area moment, $\mathrm{m}^{4}$;

[f] - standard deflection limit, mm.

Second area moment of roller unit with the hole for water supplying can be calculated as following:

$$
I=\pi\left(D^{4}-d^{4}\right) / 64
$$

where:

$\pi$ - mathematical constant;

$\mathrm{D}$ - roller table roller outer diameter, $\mathrm{m}$;

$\mathrm{d}$ - diameter of the hole in the roller table roller, $\mathrm{m}$

To compensate for possible misalignments of the roller shaft, we use roller bearings with spherical rollers (according to GOST 5721-51) [6].

The equivalent load on the bearing of the most loaded support can be calculated as following [5]:

$$
P_{\text {экв }}=R \cdot \kappa_{V} \cdot \kappa_{д} \cdot \kappa_{n p} \cdot
$$

where: 
R- load per bearing, $\mathrm{N}$;

$\mathrm{k}_{\mathrm{v}}$ - rotation factor;

$\mathrm{k}_{\text {д }}$ - dynamic factor;

$\mathrm{k}_{\text {пр }}$ - reduction factor.

The required bearing life can be calculated as following:

$$
L=\frac{60 \cdot n \cdot L_{h}}{10^{6}} .
$$

where $\mathrm{L}_{\mathrm{h}}$ - bearing life, $\mathrm{h}$.

The calculated dynamic bearing capacity can be calculated as following:

$$
C=P_{\text {экв }} \cdot \sqrt[3]{L}
$$

Support bearings can be chosen on the basis of dynamic load capacity.

\section{Summary}

The paper covers the algorithm for calculation and selection of run-out conveyor electrical motor of 5 strand billet caster. It also covers an algorithm for strength calculations of the run-out conveyor roller, which includes the calculation of the moments and forces acting on the conveyor roller and its supports, the calculation of static strength and torsion strength, calculation of roller deflection of the roller table rollers as well as the selection and verification calculation of roller table roller bearings.

\section{References}

1. A. A. Korolev, Design and engineering of the mechanisms and machines of rolling mills / -M: Metallurgy,1985.

2. M. V. Androsenko E. V. Kulikova, Calculation of the load on the rollers of the rolling mill roll during workpiece conveying, Mechanical Equipment of Metallurgical Plants: International collection of scientific papers / edited by A. G. Korchunov №1. Magnitogorsk: publishing office of Magnitogorsk State Technical University named after G. I. Nosov, (2020) 39-46.

3. R. L. Zenkov and other Mechanisms for continuous conveying Study guide,- M.: Mashinostroyeniye, 1987.

4. L. S. BelevskyV. I. Kadoshnikov, Machine parts and design basics: Study guide. Magnitogorsk: State Educational Institution of Higher Vocational Education "MGTU”, MGTU, 2008.

5. G. M. Izkovich, Strength of Materials Study guide for machine building technical colleges.- the 7th edition- M.: Vysshaya shkola, 1986.

6. Tyuteryakov Nail Sh., Savinov Alexander S., Androsenko Maria V., Rud Ksenia I., Zalilov Rustem V., Calculation of forces on the twist rollers of RTC guide fittings of PAO "MMK" section rolling mills in the process of strip coiling. //Theory and technology of metallurgical production: Nosov Magnitogorsk State Technical University, Magnitogorsk, Russia (2020) 47-49.

7. Androsenko M., Kulikova, E., Tyuteryakov, N., Pashenko, K., Yaroslavtsev, Determining the quality of continuous casting from billet caster. A. E3S Web of Conferences, 110 (2019) 01034. 